\title{
Highlighting the impact of allergenic components in emollients
}

\author{
Klaudia Ryczaj ${ }^{1}$, Karolina Dumycz ${ }^{1}$, and Wojciech Feleszko ${ }^{1}$ \\ ${ }^{1}$ The Medical University Children's Hospital
}

September 10, 2020

To the Editor,

Emollient and moisturizer preparations are recommended to improve skin barrier properties and are believed to halt the progression of the atopic march when applied from the first weeks of life in high-risk children. Such products comprise various types of substances, mainly humectants, oils, physiological lipids, preservatives, and different additives. Humectants such as glycerin or urea and oils such as paraffin, petroleum, ceramides, fatty acids, and cholesterol are essential ingredients in restoring the skin barrier. As recently demonstrated by Sindher et al., ${ }^{1}$ there is an enormous difference in the impacts of different types of cream on atopic skin, and lipid-rich products are more efficient in improvement of skin barrier function comparing to paraffine-based.

Ingredients present in emollients apart from playing their particular role in preparations can also act as haptens or proteinaceous allergens and causing side effects. Proteinaceous allergens, to which we include peanut extract, were proven to increase the risk of development of food allergy to certain foods when present in emollients applied on dry skin. ${ }^{2}$ Whereas haptens, the molecules mainly deriving from fragrance and preservative group, may cause irritation or allergic contact dermatitis (ACD). Due to impaired skin barrier function and frequent application of products containing haptens, children with atopic dermatitis are highly prone to ACD. ${ }^{3}$ Studies through the past decade indicate that the prevalence of ACD in children is increasing and can start even in early infancy. ${ }^{3}$ European guidelines for the treatment of atopic dermatitis recommend using emollients devoid of proteinaceous allergens and haptens that were known to cause contact allergy frequently, especially in the most vulnerable age group before the age of 2 years. ${ }^{4}$

The recent two large randomized control BEEP ${ }^{5}$ and PreventADALL trials, ${ }^{6}$ surprisingly, found that the use of emollients had no beneficial effects on preventing atopic dermatitis. However, an increased risk of skin infections or food allergies was noted, though without statistical significance. ${ }^{5}$ One of the emollients used in the BEEP trial was DoubleBase gel containing $15 \%$ isopropyl myristate (IPM) which is considered a hapten in the Cosmetic series (https://www.chemotechnique.se, accessed August 24, 2020). IPM is a clinically relevant sensitizer ${ }^{7}$ which, moreover, frequently cause irritant reactions. ${ }^{8}$

Recently, Brough et al. ${ }^{9}$ highlighted that a disrupted skin barrier, particularly in early life, is a direct risk factor for developing food allergies. Following this lead, it can be assumed that children receiving preparations containing haptens on the skin, especially with disrupted barrier function, may experience inflammation and therefore be of increased risk of food allergy. The results of a long-term follow-up BEEP study are eagerly anticipated to see if the trend towards increased allergy in the intervention group will continue.

We know, that selecting a well-designed emollient, that means: deprived of potential sentitizers might be difficult, since there is an abundance of potential sensitizers in cosmetics, even for the youngest children, and haptens are found in more than $85 \%$ of products as recently demonstrated by Dumycz et al.. ${ }^{10}$ We hypothesize, that careful selection of emollient preparation may still contribute to better clinical effects and should consider the presence of lipids as well as the absence of potentially harmful ingredients, in particular when used in infants and young children. 
Klaudia Ryczaj MD*, Karolina Dumycz MD*, Wojciech Feleszko MD PhD*

* Department of Pediatric Pneumonology and Allergy, Medical University of Warsaw, Żwirki i Wigury 63A, 02-091 Warsaw, Poland

Corresponding author: Wojciech Feleszko MD PhD, e-mail: wojciech.feleszko@kliniczny.pl

1. Sindher S, Alkotob SS, Shojinaga MN, et al. Pilot study measuring transepidermal water loss (TEWL) in children suggests trilipid cream is more effective than a paraffin-based emollient [published online ahead of print, 2020 Mar 16]. Allergy . 2020;10.1111/all.14275. doi:10.1111/all.14275.

2. Lack G, Fox D, Northstone K, Golding J; Avon Longitudinal Study of Parents and Children Study Team. Factors associated with the development of peanut allergy in childhood. $N$ Engl J Med . 2003;348(11):977985.

3. de Waard-van der Spek FB, Andersen KE, Darsow U, et al. Allergic contact dermatitis in children: which factors are relevant? (review of the literature). Pediatr Allergy Immunol . 2013;24(4):321-329.

4. Wollenberg A, Barbarot S, Bieber T, et al. Consensus-based European guidelines for treatment of atopic eczema (atopic dermatitis) in adults and children: part I [published correction appears in J Eur Acad Dermatol Venereol. 2019 Jul;33(7):1436]. J Eur Acad Dermatol Venereol . 2018;32(5):657-682.

5. Chalmers JR, Haines RH, Bradshaw LE, et al. Daily emollient during infancy for prevention of eczema: the BEEP randomised controlled trial.Lancet . 2020;395(10228):962-972.

6. Skjerven HO, Rehbinder EM, Vettukattil R, et al. Skin emollient and early complementary feeding to prevent infant atopic dermatitis (PreventADALL): a factorial, multicentre, cluster-randomised trial [published correction appears in Lancet. 2020 Mar 21;395(10228):e53]. Lancet . 2020;395(10228):951-961.

7. Ada S, Seçkin D. Patch testing in allergic contact dermatitis: is it useful to perform the cosmetic series in addition to the European standard series?. J Eur Acad Dermatol Venereol . 2010;24(10):1192-1196.

8. Uter W, Schnuch A, Geier J, Lessmann H. Isopropyl myristate recommended for aimed rather than routine patch testing. Contact Dermatitis . 2004;50(4):242-244.

9. Brough HA, Nadeau KC, Sindher SB, et al. Epicutaneous sensitization in the development of food allergy: What is the evidence and how can this be prevented? [published online ahead of print, 2020 Apr 6].Allergy . 2020;10.1111/all.14304. doi:10.1111/all.14304.

10. Dumycz K, Kunkiel K, Feleszko W. Cosmetics for neonates and infants: haptens in products' composition. Clin Transl Allergy . 2019;9:15. 